\title{
Variability of total soluble phenolic compounds and antioxidant activity in a collection of tetraploid wheat
}

\author{
Antonella Pasqualone ${ }^{1 *}$, Laura Nunzia Delvecchio ${ }^{1}$, Giacomo Mangini ${ }^{2}$, Francesca Taranto ${ }^{2}$ and Antonio Blanco ${ }^{2}$ \\ ${ }^{1}$ Food Science and Technology Unit, University of Bari, Department of Soil, Plant and Food Sciences, Via Amendola, \\ 165/A, I 70126, Bari, Italy \\ ${ }^{2}$ Plant Breeding Unit, University of Bari, Department of Soil, Plant and Food Sciences, Via Amendola, 165/A, I 70126, Bari, Italy \\ e-mail*: antonella.pasqualone@uniba.it
}

\begin{abstract}
The total soluble phenolic compounds (TSPC) and antioxidant activity (AA) of 113 tetraploid wheat samples including cultivars, landraces, and wild accessions of different Triticum turgidum subspecies, were assessed to point out potential sources for cereal-based functional foods. TSPC ranged from 1.28 to $3.15 \mathrm{mg} \mathrm{g}^{-1}$ as ferulic acid equivalents and $\mathrm{AA}$, assessed by 2,2-diphenyl-1-picrylhydrazyl radical scavenging capacity test, ranged from $47.5 \%$ to $81.7 \%$. Among cultivars of ssp. durum, the highest levels were observed in 'Timilia' and 'Svevo', while the ssp. dicoccoides showed the highest TSPC and AA among the accessions. The principal component analysis of data discriminated cultivars from wild accessions, and PC1 explained about $62 \%$ of variability. The TSPC were negatively correlated with thousand-kernel weight and grain yield per spike, while were positively correlated with AA, grain protein content, polyphenol oxidase activity, and brown index of whole meal and dough. The cultivar 'Langdon' coupled high TSPC and low brownness.
\end{abstract}

Key words: Triticum turgidum, phenolics, antioxidant activity, PCA, grain yield, brown index

\section{Introduction}

Wheat is one of the most diffused cereals and is characterized by a wide range of cultivation: from $67^{\circ} \mathrm{N}$ in Scandinavia and Russia to $45^{\circ} \mathrm{S}$ in Argentina, including elevated regions in the tropics and sub-tropics (Feldman 1995). Whole-wheat diet has been shown to reduce the incidence of type-2 diabetes, cardiovascular diseases, and colon cancer (Ferguson and Harris 1999, De Munter et al. 2007). The beneficial health effects have mainly been ascribed to dietary fiber and to some antioxidant components associated to it, in particular phenolic compounds (Ferguson and Harris 1999).

Phenolic compounds are major secondary metabolites of plants. They occur in wheat grains as: i) soluble free phenolic acids; ii) soluble conjugated phenolics bound to low molecular mass components such as saccharides or organic acids; iii) insoluble bound forms of phenolics, linked to polymers of the plant cell wall (Klepacka and Fornal 2006). Although the majority of phenolics occur in bound forms, great interest is put towards the soluble forms due to their bioavailability (Mateo Anson et al. 2009, Moore and Hao 2012). Wheat phenolics are primarily derivatives of benzoic and cinnamic acids, dominated by ferulic acid (Klepacka and Fornal 2006). Their chemical structure renders them able to scavenge or neutralize free radicals by donating electrons (Soobrattee et al. 2005), and thereby to reduce or minimize oxidative damage to proteins, DNA, and membrane lipids (Tucker and Robards 2008). Due to these antioxidant properties, assessed in several researches (Zhou and Yu 2004, Menga et al. 2010, Van Hung et al. 2011), phenolic compounds are one of the factors contributing to whole-wheat health benefits.

While the phenolic content of hexaploid wheat has been widely studied (Adom et al. 2003, Beta et al. 2005, Mpofu et al. 2006, Verma et al. 2008, Yu 2008, Revanappa and Salimath 2011, Moore and Hao 2012), minor attention has been devoted to tetraploid wheat. The few reports available focused only on durum wheat cultivars (Lempereur et al. 1997, Dinelli et al. 2009, Menga et al. 2010, Acquistucci et al. 2013), and a single report is about other free-threshing or hulled subspecies, wild or domesticated (Abdel-Aal and Rabalski 2008). Moreover, the number of samples studied was limited, ranging between 3 and 30.

In a previous research, a collection composed of a large set of tetraploid wheat samples including durum wheat cultivars, landraces, and wild accessions of different Triticum turgidum subspecies, has been assembled and screened for genetic diversity by molecular markers and pedigree data (Laidò et al. 2013). The population structure of this tetraploid wheat collection partially reflects the evolutionary history of Triticum turgidum L. subspecies and the genetic potential of landraces and wild accessions for the detection of unexplored alleles. Moreover, the variability of protein content, browning level, and polyphenol oxidase activity within this collection has been determined, due to their importance for end-product quality (Taranto et al. 2012). 
A. Pasqualone et al. (2014) 23: 307-316

The aim of this work was to evaluate the variability of total soluble phenolic compounds and antioxidant activity of the above cited tetraploid wheat collection, to identify the best sources to be used for cereal-based functional foods. Moreover, the aim was to point out possible correlations between phenolic compounds and the other qualitative traits previously assessed in the same collection.

\section{Materials and methods}

\section{Samples}

Grains of 113 tetraploid wheats were considered: 65 cultivars and one breeding line of durum wheat (Triticum turgidum ssp. durum (Desf.) Husnot), listed in Table 1, and 47 landraces and wild accessions of various Triticum turgidum subspecies, listed in Table 2. Samples were grown in the experimental field of the University of Bari at Valenzano (Bari, Italy) in 2010, in a randomized complete block design with three replicates and plots consisting of $1 \mathrm{~m}$ rows, $30 \mathrm{~cm}$ apart, with 50 germinating seeds per plot. During the growing season, $100 \mathrm{~kg} \mathrm{ha}^{-1}$ of N was applied and standard cultivation practices were adopted. Plots were hand-harvested at maturity and grain yield per spike (GYS) was determined by dividing grain yield per row by the number of spikes per row (about 35 spikes). A $15 \mathrm{~g}$ seed sample per plot was used to determine thousand-kernel weight (KW).

\section{Basic physico-chemical analyses}

Harvested grain samples from each plot were separately milled on a laboratory mill equipped with $1 \mathrm{~mm}$ sieve (Cyclotec Sample Mill, Tecator Foss, Hillerød, Denmark). Moisture content was determined at $105^{\circ} \mathrm{C}$ by means of an automatic moisture analyzer (Radwag Wagi Elektroniczne, Radom, Poland). Grain protein content (GPC) was determined on $2 \mathrm{~g}$ of whole meal by using a dual beam near infrared reflectance spectrophotometer (Zeutec Spectra Alyzer Premium, Zeutec Büchi, Rendsburg, Germany). Colorimetric evaluations of brown index (BI, defined as $\left.100-L^{*}\right)$ were carried out on whole meal and dough by means of the reflectance colorimeter Chroma Meter CR300 (Minolta, Osaka, Japan) as reported in Taranto et al. (2012). Whole meal (2.5 g) was placed into the granular materials attachment CR-A50 (Minolta, Osaka, Japan) of the colorimeter to obtain a smooth surface suitable for color readings. Dough was prepared by hand-kneading $1 \mathrm{~g}$ of whole meal from each sample with $700 \mu$ listilled water in a clean porcelain capsule, until water was completely absorbed and dough appeared smooth and elastic. Then, dough was compressed between two Petri plates to obtain uniformly thick discs.

\section{Determination of polyphenol oxidase (PPO) activity}

PPO (E.C. 1.14.18.1) was measured by incubating 30 seeds in $5 \mathrm{ml}$ of $0.01 \mathrm{M}$ disodium tyrosinate (pH 10.7) at 37 ${ }^{\circ} \mathrm{C}$ for 19 hours. Then, after removal of the seeds, the absorbance of the solution was measured at $405 \mathrm{~nm}$ by a Cary 60 UV-vis spectrophotometer (Agilent Technologies Inc., Santa Clara, CA, USA).

\section{Quantification of total soluble phenolic compounds (TSPC)}

TSPC (composed of soluble free phenolic acids and soluble phenolics bound to low molecular mass components) were extracted by adding $1 \mathrm{ml}$ of methanol to $0.1 \mathrm{~g}$ whole meal, then purging with stream of nitrogen, keeping on orbital shaker at $200 \mathrm{rev} \mathrm{min}^{-1}$, for $2 \mathrm{~h}$, in the dark, and centrifuging at 7,000 $\times \mathrm{g}$ for $5 \mathrm{~min}$. The recovered supernatant was subjected to Folin-Ciocalteu reaction as follows. The reaction mixture contained $100 \mu$ supernatant, $500 \mu \mathrm{l}$ Folin-Ciocalteu reagent (Sigma-Aldrich Chemical Co., St. Louis, MO, USA) and $2 \mathrm{ml}$ of 15\% (w/v) sodium carbonate. The final volume was made up to $10 \mathrm{ml}$ with distilled water. After $1 \mathrm{~h}$ in the dark, and centrifugation at $12,000 \times g$ for $3 \mathrm{~min}$ to precipitate any particles, the absorbance of the solution was measured at $765 \mathrm{~nm}$ by a Cary 60 UV-Vis spectrophotometer (Agilent Technologies Inc., Santa Clara, CA, USA). A calibration curve was built by methanol solutions of ferulic acid (Sigma-Aldrich Chemical Co., St. Louis, MO, USA) at concentrations between 0.1 and $2 \mathrm{gl}^{-1}\left(\mathrm{y}=0.0007 \mathrm{x}+0.0089 ; \mathrm{r}^{2}=0.9985\right)$. The results were expressed as $\mathrm{mg}$ ferulic acid equivalents (FAE) per $\mathrm{g}$, being ferulic acid the predominant phenolic acid in wheat. All tests were carried out in triplicate.

\section{Determination of antioxidant activity (AA)}

AA was assessed by the 2,2-diphenyl-1-picrylhydrazyl (DPPH) radical scavenging capacity assay. An amount of 500 $\mu \mathrm{l}$ of the same extract prepared for TSPC determination was added to $1.5 \mathrm{ml}$ of freshly-prepared $60 \mu \mathrm{M}$ DPPH radical solution (Sigma-Aldrich Chemical Co., St. Louis, MO, USA) in methanol. After 30 min of reaction in the dark, the absorbance of the solution was measured at $515 \mathrm{~nm}$ by a Cary $60 \mathrm{UV}$-Vis spectrophotometer (Agilent Technologies Inc., Santa Clara, CA, USA). At the same wavelength, but at $t=0 \mathrm{~min}$, it was also read the absorbance of 
the methanol solution of DPPH radical without sample (control). Methanol was the blank. The AA of the samples was expressed as percent capacity of scavenging the DPPH radical (SC\%) according to the following equation:

$\mathrm{SC} \%=\left(1-\right.$ Abs of sample $_{\mathrm{t}=30^{\prime}} /$ Abs of control $\left.{ }_{\mathrm{t}=0}\right) \times 100$

where Abs of sample $e_{t=30^{\prime}}$ was the absorbance of DPPH radical solution + sample at $t=30$ min; Abs of control ${ }_{t=0}$ was the absorbance of the DPPH radical solution at $t=0 \mathrm{~min}$.

A calibration curve was built by using solutions of the standard antioxidant 6-hydroxy-2,5,7,8-tetramethylchroman2-carboxylic acid (Trolox) (Sigma-Aldrich Chemical Co., St. Louis, MO, USA) at concentrations between 0.02 and 1 $\mathrm{M}\left(\mathrm{y}=-0.008 \mathrm{x}+0.6087 ; r^{2}=0.9971\right)$, to express the results also as $\mu \mathrm{mol}$ Trolox equivalents $\mathrm{g}^{-1}$.

All tests were carried out in triplicate.

\section{Statistical analyses}

Standard ANOVA (with sample as fixed factor and replicate as random factor) and principal component analysis (PCA) were performed using the software MSTAT-C (Michigan State University, East Lansing, MI). The Fisher's least significant difference $\left(\mathrm{LSD}_{0.05}\right)$ was applied to test the differences between samples at $5 \%$ significance level. The estimations of values of TSPC adjusted to GYS (GYS-adj TSPC) and KW (KW-adj TSPC) were calculated by covariance analysis and expressed by the following relationship:

$\mathrm{Y}_{\mathrm{m}}=\mathrm{Y}_{\mathrm{j}}+b\left(\mathrm{X}_{\mathrm{m}}-\mathrm{X}_{\mathrm{j}}\right)$

where $Y_{m}$ and $Y_{j}$ are the mean TSPC and the value of individual samples, respectively; $X_{m}$ and $X_{j}$ are the mean GYS (or KW) and the value of individual samples, respectively, and $b$ is the regression coefficient between the traits.

\section{Results and discussion Variability of TSPC and AA}

Data about TSPC and AA of 65 durum cultivars, one breeding line, and 47 tetraploid landraces and wild accessions are presented in Tables 1 and 2 . The analysis of variance revealed that both among replications and among samples significant differences occurred $(p<0.001)$ (Table 3).

Overall, the TSPC ranged from 1.28 to $3.15 \mathrm{mg} \mathrm{FAE} \mathrm{g}^{-1}$. The majority of durum cultivars showed a phenolic content ranging from 1.87 to $2.40 \mathrm{mg} \mathrm{FAE} \mathrm{g}^{-1}$, while the majority of landraces and accessions was characterized by higher values, comprised from 2.05 to $3.15 \mathrm{mg} \mathrm{FAE} \mathrm{g}^{-1}$. The AA, assessed by the DPPH radical scavenging capacity (SC) assay, varied from 47.5 to $81.7 \%$ (corresponding to a range from 1.32 to $2.44 \mu \mathrm{mol}$ Trolox ${ }^{-1}$ ) within the whole collection, with the highest values in the accessions of ssp. dicoccum and ssp. dicoccoides.

Individually, the durum cultivars with the highest TSPC levels were 'Timilia' and 'Svevo', both with 2.48 mg FAE $\mathrm{g}^{-1}$, while the lowest values were ascertained in 'Altar84', 'Cosmodur', and 'Sansone' (1.52, 1.54 and 1.57 mg FAE $\mathrm{g}^{-1}$, respectively). The highest AA for cultivars accounted for about $75 \%$ SC (or $2.28 \mu \mathrm{mol}$ Trolox g ${ }^{-1}$ ), assessed in 'Zenit' and 'AC Navigator'. The minimum value was ascertained in 'Simeto'.

Although focusing on a limited number of samples, other authors evaluated the phenolic compounds of ssp. durum. Lempereur et al. (1997) analysed different milling fractions from 5 cultivars and in whole meal assessed 0.69$2.44 \mathrm{mg} \mathrm{FAE} \mathrm{g}^{-1}$. Moreover, they observed that phenolic compounds were much more concentrated in bran and aleurone layer than in endosperm and germ. Recently, Menga et al. (2010) ascertained 0.78-0.95 mg FAE g in 30 cultivars. However, the absence of standardised protocols to extract, measure, and express the results regarding these phytochemicals makes comparisons between studies rather difficult: phenolics are extracted from wheat by using several polar solvents, usually ethanol, methanol or acetone, combined with different procedures, and it has been reported that varying the extracting solvent can significantly alter their estimations (Zhou and Yu 2004). In addition, environmental factors during growing season can affect the size of the seeds and, in turn, phenolic content (Mpofu et al. 2006). Climatic factors associated to drought stress and high temperature during grain filling may lead to high phenolic contents (Menga et al. 2010). Moreover, organic cultivation can induce higher phenolic levels in wheat than conventional agriculture (Żuchowski et al. 2009), and similar effects have been observed by using composted sewage sludge as fertilizer (Pasqualone et al. 2014). 
A. Pasqualone et al. (2014) 23: 307-316

Table 1. Total soluble phenolic compounds (TSPC) and antioxidant activity (AA) of 65 durum cultivars and one breeding line (L092) included in a tetraploid wheat collection grown at Valenzano (Bari, Italy) in 2010. Samples were grouped according to the year of release.

\begin{tabular}{|c|c|c|c|c|c|c|c|c|c|c|c|}
\hline \multirow{2}{*}{ Cultivar } & \multicolumn{3}{|c|}{$\begin{array}{l}\text { TSPC } \\
(m g \text { FAE g-1 db) })^{a, b}\end{array}$} & \multicolumn{2}{|l|}{$A A^{a}$} & \multirow{2}{*}{ Cultivar } & \multicolumn{3}{|c|}{$\begin{array}{l}\text { TSPC } \\
\left(m g \text { FAE g-1 db) }{ }^{a, b}\right.\end{array}$} & \multicolumn{2}{|l|}{$\mathrm{AA}^{\mathrm{a}}$} \\
\hline & $\begin{array}{c}\text { Obser- } \\
\text { ved }\end{array}$ & $\begin{array}{l}\text { GYS- } \\
\text { adj }^{c}\end{array}$ & $\begin{array}{l}\mathrm{KW}- \\
\mathrm{adj}^{\mathrm{d}}\end{array}$ & $(\mathrm{SC} \%)^{\mathrm{e}}$ & $\begin{array}{c}(\mu \mathrm{mol} \\
\text { Trolox g-1) }\end{array}$ & & $\begin{array}{l}\text { Obser- } \\
\text { ved }\end{array}$ & $\begin{array}{l}\text { GYS- } \\
\operatorname{adjc}^{c}\end{array}$ & $K W-\operatorname{adj}^{d}$ & $(\mathrm{SC} \%)^{\mathrm{e}}$ & $\begin{array}{c}(\mu \mathrm{mol} \\
\text { Trolox g-1 })^{f}\end{array}$ \\
\hline \multicolumn{6}{|c|}{ Released before 1971} & \multicolumn{6}{|c|}{ Released between 1991 and 2008} \\
\hline Sharm 5 & 1.59 & 1.57 & 1.62 & 57.7 & 1.84 & Cosmodur & 1.54 & 1.59 & 1.56 & 74.4 & 2.24 \\
\hline Capeiti-8 & 1.70 & 1.70 & 1.74 & 52.5 & 1.48 & Normanno & 1.69 & 1.62 & 1.75 & 52.0 & 1.56 \\
\hline Cappelli & 1.70 & 1.52 & 1.45 & 61.2 & 1.76 & L092 & 1.70 & 1.78 & 1.84 & 62.6 & 1.96 \\
\hline Aziziah & 2.12 & 2.31 & 2.20 & 61.4 & 1.84 & Saragolla & 1.80 & 1.61 & 1.81 & 52.1 & 1.52 \\
\hline Taganrog & 2.18 & 2.09 & 1.94 & 57.9 & 1.76 & Ancomarzio & 1.82 & 1.72 & 1.84 & 60.6 & 1.84 \\
\hline Russello & 2.19 & 2.06 & 2.04 & 66.7 & 2.00 & Ares & 1.83 & 1.70 & 1.78 & 64.1 & 1.84 \\
\hline Langdon & 2.25 & 2.34 & 2.28 & 58.4 & 2.04 & Dauno & 1.84 & 1.62 & 1.80 & 63.1 & 1.96 \\
\hline Grifoni & 2.31 & 2.27 & 2.20 & 65.8 & 2.00 & Parsifal & 1.85 & 1.75 & 1.82 & 55.9 & 1.68 \\
\hline Kiperounda & 2.40 & 2.52 & 2.50 & 70.1 & 2.20 & Ciccio & 1.89 & 1.70 & 1.81 & 54.4 & 1.72 \\
\hline \multirow[t]{2}{*}{ Timilia } & 2.48 & 2.66 & 2.60 & 63.1 & 1.88 & Fiore & 1.90 & 1.82 & 1.95 & 60.1 & 1.84 \\
\hline & & & & & & Iride & 1.90 & 1.70 & 1.89 & 57.4 & 1.64 \\
\hline Mean & 2.09 & 2.10 & 2.06 & 61.5 & 1.88 & Giotto & 1.92 & 1.91 & 1.90 & 63.2 & 1.88 \\
\hline SD & 0.32 & 0.39 & 0.37 & 5.2 & 0.20 & Grecale & 1.93 & 1.78 & 1.98 & 63.1 & 1.88 \\
\hline Min & 1.59 & 1.52 & 1.45 & 52.5 & 1.48 & Saadi & 1.98 & 1.96 & 1.95 & 60.3 & 1.84 \\
\hline \multirow[t]{2}{*}{ Max } & 2.48 & 2.66 & 2.60 & 70.1 & 2.20 & PR22D89 & 1.99 & 1.78 & 1.82 & 60.6 & 1.92 \\
\hline & & & & & & Tiziano & 1.99 & 1.81 & 1.83 & 61.9 & 2.12 \\
\hline \multicolumn{6}{|c|}{ Released between 1971 and 1990} & AC Navigator & 2.01 & 1.98 & 2.04 & 75.3 & 2.28 \\
\hline Ofanto & 1.28 & 1.20 & 1.28 & 62.9 & 1.92 & Cirillo & 2.04 & 1.97 & 1.99 & 63.4 & 2.00 \\
\hline Altar84 & 1.52 & 1.41 & 1.41 & 57.2 & 1.72 & Strongfield & 2.09 & 2.10 & 2.12 & 68.3 & 2.12 \\
\hline Sansone & 1.57 & 1.49 & 1.36 & 55.7 & 1.64 & Arcobaleno & 2.11 & 1.96 & 2.05 & 50.2 & 1.48 \\
\hline Appulo & 1.72 & 1.69 & 1.65 & 49.5 & 1.48 & Zenit & 2.11 & 2.07 & 2.12 & 75.8 & 2.28 \\
\hline Arcangelo & 1.78 & 1.78 & 1.80 & 59.7 & 1.80 & Kronos & 2.19 & 1.97 & 2.14 & 62.0 & 1.88 \\
\hline Messapia & 1.81 & 1.68 & 1.71 & 54.6 & 1.72 & Pedroso & 2.22 & 2.09 & 2.16 & 57.6 & 1.72 \\
\hline Mida & 1.87 & 1.84 & 1.88 & 67.9 & 2.04 & Duetto & 2.23 & 2.15 & 2.19 & 58.6 & 1.72 \\
\hline Primadur & 1.88 & 1.90 & 2.07 & 74.4 & 2.24 & Colosseo & 2.24 & 2.21 & 2.19 & 55.7 & 1.68 \\
\hline Simeto & 1.90 & 1.72 & 1.83 & 47.5 & 1.32 & Ariosto & 2.26 & 2.08 & 2.32 & 65.0 & 1.88 \\
\hline Antas & 1.92 & 1.88 & 1.89 & 60.3 & 1.92 & Claudio & 2.27 & 2.34 & 2.32 & 57.3 & 1.68 \\
\hline Duilio & 1.94 & 1.93 & 1.93 & 68.1 & 2.00 & Doral & 2.32 & 2.32 & 2.29 & 60.7 & 1.96 \\
\hline Mexicali 75 & 1.95 & 1.81 & 1.88 & 55.4 & 1.80 & UC1113 & 2.32 & 2.41 & 2.48 & 63.9 & 1.92 \\
\hline Creso & 1.98 & 1.90 & 2.01 & 58.1 & 1.76 & Svevo & 2.48 & 2.49 & 2.50 & 59.7 & 2.04 \\
\hline Valnova & 2.00 & 1.85 & 1.96 & 52.9 & 1.60 & & & & & & \\
\hline Brindur & 2.01 & 1.93 & 1.98 & 64.4 & 1.96 & Mean & 2.02 & 1.93 & 2.01 & 61.3 & 1.87 \\
\hline Neodur & 2.03 & 1.96 & 1.99 & 56.8 & 1.60 & SD & 0.22 & 0.25 & 0.23 & 6.3 & 0.21 \\
\hline Isa & 2.08 & 2.02 & 1.91 & 55.8 & 1.76 & Min & 1.54 & 1.59 & 1.56 & 50.2 & 1.48 \\
\hline Karel & 2.11 & 2.06 & 2.14 & 71.3 & 2.16 & Max & 2.48 & 2.49 & 2.50 & 75.8 & 2.28 \\
\hline Produra & 2.11 & 1.95 & 2.04 & 69.2 & 2.08 & & & & & & \\
\hline Ambral & 2.15 & 2.00 & 2.09 & 63.9 & 1.92 & & & & & & \\
\hline Appio & 2.15 & 2.15 & 2.14 & 61.7 & 1.96 & All cultivars & & & & & \\
\hline Athena & 2.21 & 1.99 & 2.21 & 58.6 & 1.64 & Mean & 2.00 & 1.94 & 1.99 & 61.4 & 1.88 \\
\hline Latino & 2.22 & 1.97 & 2.20 & 67.8 & 2.12 & SD & 0.25 & 0.29 & 0.27 & 6.4 & 0.21 \\
\hline Polesine & 2.23 & 2.49 & 2.13 & 69.3 & 2.08 & Min & 1.28 & 1.20 & 1.28 & 47.5 & 1.32 \\
\hline Belfuggito & 2.27 & 2.33 & 2.35 & 73.0 & 2.16 & Max & 2.48 & 2.66 & 2.60 & 75.8 & 2.28 \\
\hline Tito & 2.46 & 2.39 & 2.50 & 62.5 & 1.88 & & & & & & \\
\hline Mean & 1.97 & 1.90 & 1.94 & 61.5 & 1.84 & & & & & & \\
\hline SD & 0.26 & 0.28 & 0.29 & 7.2 & 0.23 & & & & & & \\
\hline Min & 1.28 & 1.20 & 1.28 & 47.5 & 1.32 & & & & & & \\
\hline Max & 2.46 & 2.49 & 2.50 & 74.4 & 2.24 & & & & & & \\
\hline
\end{tabular}

${ }^{\mathrm{a}}$ Mean of three field replications; ${ }^{\mathrm{b} F A E}=$ ferulic acid equivalents; ${ }^{\mathrm{C} G Y S}$-adj $=$ adjusted to grain yield per spike; ${ }^{\mathrm{d}} \mathrm{KW}$-adj $=$ adjusted to thousand-kernels weight; ${ }^{\text {SSC}}$ = DPPH scavenging capacity percentage; 'Trolox = 6-hydroxy-2,5,7,8-tetramethylchroman-2-carboxylic acid. 
Table 2. Total soluble phenolic compounds (TSPC) and antioxidant activity (AA) of landraces and wild accessions of Triticum turgidum included in a tetraploid wheat collection grown at Valenzano (Bari, Italy) in 2010.

\begin{tabular}{|c|c|c|c|c|c|c|c|c|c|c|c|}
\hline \multirow[b]{2}{*}{ Accession } & \multicolumn{3}{|c|}{$\begin{array}{c}\text { TSPC } \\
\left(m g \text { FAE g-1 db) }{ }^{a, b}\right.\end{array}$} & \multicolumn{2}{|c|}{$A A^{a}$} & \multirow[b]{2}{*}{ Accession } & \multicolumn{3}{|c|}{$\begin{array}{c}\text { TSPC } \\
\left(\mathrm{mg} \mathrm{FAE} \mathrm{g}^{-1} \mathrm{db}\right)^{\mathrm{a}, \mathrm{b}}\end{array}$} & \multicolumn{2}{|c|}{$A A^{a}$} \\
\hline & $\begin{array}{l}\text { Obser- } \\
\text { ved }\end{array}$ & $\begin{array}{l}\text { GYS- } \\
\operatorname{adj}^{c}\end{array}$ & $\begin{array}{l}\mathrm{KW}- \\
\operatorname{adj}^{\mathrm{d}}\end{array}$ & $(\mathrm{SC} \%)^{\mathrm{e}}$ & $\begin{array}{c}\text { ( } \mu \mathrm{mol} \\
\text { Trolox } \\
\left.\mathrm{g}^{-1}\right)^{f}\end{array}$ & & $\begin{array}{l}\text { Obser- } \\
\text { ved }\end{array}$ & $\begin{array}{l}\text { GYS- } \\
\text { adjc }^{c}\end{array}$ & $\begin{array}{l}\mathrm{KW}- \\
\text { adj }^{\mathrm{d}}\end{array}$ & $(\mathrm{SC} \%)^{\mathrm{e}}$ & $\begin{array}{l}(\mu \mathrm{mol} \\
\text { Trolox } \\
\left.\mathrm{g}^{-1}\right)^{f}\end{array}$ \\
\hline \multicolumn{6}{|c|}{ ssp. turanicum (Khorasan wheat) } & \multicolumn{6}{|c|}{ ssp. carthlicum (Persian wheat) } \\
\hline PI 113393 & 1.67 & 1.77 & 1.54 & 61.3 & 1.84 & PI 94755 & 2.01 & 2.24 & 2.25 & 63.8 & 1.92 \\
\hline PI 306665 & 1.74 & 1.35 & 1.38 & 69.8 & 2.16 & Citr 7665 & 2.19 & 2.37 & 2.32 & 71.4 & 2.16 \\
\hline PI 352514 & 2.05 & 1.84 & 1.73 & 49.4 & 1.36 & PI 341800 & 2.36 & 2.71 & 2.60 & 65.6 & 1.96 \\
\hline PI 67343 & 2.08 & 2.07 & 1.90 & 66.3 & 2.00 & & & & & & \\
\hline PI 167481 & 2.12 & 2.22 & 2.08 & 55.5 & 1.68 & Mean & 2.19 & 2.44 & 2.39 & 66.9 & 2.00 \\
\hline PI 68287 & 2.18 & 2.02 & 1.98 & 49.2 & 1.32 & SD & 0.18 & 0.24 & 0.18 & 4.0 & 0.13 \\
\hline PI 184526 & 2.20 & 2.49 & 2.41 & 64.1 & 1.96 & Min & 2.01 & 2.24 & 2.25 & 63.8 & 1.92 \\
\hline PI 191599 & 2.24 & 2.14 & 1.92 & 56.5 & 1.72 & Max & 2.36 & 2.71 & 2.60 & 71.4 & 2.16 \\
\hline Mean & 2.04 & 1.99 & 1.87 & 59.0 & 1.76 & ssp. dicoccum (er & mer) & & & & \\
\hline SD & 0.21 & 0.34 & 0.32 & 7.6 & 0.30 & ISC_Foggia_171 & 2.40 & 2.69 & 2.69 & 56.8 & 1.64 \\
\hline Min & 1.67 & 1.35 & 1.38 & 49.2 & 1.32 & MG 5350 & 2.48 & 2.78 & 2.73 & 66.2 & 2.00 \\
\hline \multirow[t]{2}{*}{ Max } & 2.24 & 2.49 & 2.41 & 69.8 & 2.16 & MG15516/1 & 2.49 & 2.69 & 2.65 & 73.0 & 2.24 \\
\hline & & & & & & MG 4387 & 2.55 & 2.66 & 2.75 & 64.9 & 2.00 \\
\hline \multicolumn{6}{|c|}{ ssp. polonicum (Polish wheat) } & Molise Sel. Colli & 2.60 & 2.76 & 2.61 & 69.2 & 2.04 \\
\hline PI 223171 & 1.47 & 1.20 & 1.05 & 68.2 & 2.08 & MG 5416/1 & 2.64 & 3.00 & 2.86 & 81.7 & 2.36 \\
\hline PI 366117 & 1.64 & 1.83 & 1.72 & 71.6 & 2.12 & MG5293/1 & 2.67 & 3.16 & 3.00 & 76.1 & 2.32 \\
\hline PI 272564 & 2.05 & 2.23 & 1.87 & 73.7 & 2.16 & MG5473 & 2.69 & 2.74 & 2.62 & 77.1 & 2.32 \\
\hline PI 289606 & 2.11 & 2.26 & 2.13 & 68.1 & 1.92 & MG5323 & 2.73 & 3.09 & 3.03 & 75.7 & 2.24 \\
\hline PI 286547 & 2.13 & 2.12 & 2.16 & 65.3 & 2.04 & & & & & & \\
\hline PI 349051 & 2.13 & 2.06 & 1.98 & 63.0 & 1.92 & Mean & 2.58 & 2.84 & 2.77 & 71.2 & 2.12 \\
\hline PI 210845 & 2.14 & 2.20 & 1.82 & 61.8 & 1.92 & SD & 0.11 & 0.19 & 0.16 & 7.6 & 0.15 \\
\hline \multirow[t]{2}{*}{ PI 306549} & 2.27 & 2.49 & 2.29 & 75.5 & 2.28 & Min & 2.40 & 2.66 & 2.61 & 56.8 & 1.64 \\
\hline & & & & & & Max & 2.73 & 3.16 & 3.03 & 81.7 & 2.36 \\
\hline Mean & 1.99 & 2.05 & 1.88 & 68.4 & 2.04 & & & & & & \\
\hline SD & 0.28 & 0.39 & 0.38 & 4.9 & 0.13 & ssp. dicoccoides & & & & & \\
\hline Min & 1.47 & 1.20 & 1.05 & 61.8 & 1.92 & PI 470944 & 2.29 & 2.42 & 2.19 & 75.9 & 2.40 \\
\hline \multirow[t]{2}{*}{ Max } & 2.27 & 2.49 & 2.29 & 75.5 & 2.28 & MG4328/61 & 2.50 & 2.88 & 2.78 & 80.0 & 2.40 \\
\hline & & & & & & MG4330/66 & 2.54 & 2.92 & 2.80 & 68.1 & 2.16 \\
\hline \multicolumn{2}{|c|}{ ssp. turgidum } & & & & & PI 481539 & 2.84 & 3.30 & 3.26 & 78.9 & 2.36 \\
\hline PI 157983 & 1.95 & 1.70 & 1.90 & 60.0 & 1.84 & MG 4343 & 3.04 & 3.47 & 3.42 & 68.5 & 2.12 \\
\hline PI 290522 & 1.99 & 1.84 & 2.11 & 78.9 & 2.40 & PI 355459 & 3.15 & 3.43 & 3.53 & 73.4 & 2.20 \\
\hline PI 286075 & 2.08 & 2.08 & 2.21 & 78.4 & 2.36 & PI 352323 & n.d. ${ }^{g}$ & n.d. & n.d. & n.d. & n.d. \\
\hline PI 56263 & 2.16 & 1.93 & 1.99 & 60.1 & 1.80 & & & & & & \\
\hline PI 352544 & 2.17 & 2.24 & 2.12 & 79.3 & 2.36 & Mean & 2.73 & 3.07 & 3.00 & 74.1 & 2.28 \\
\hline PI 191104 & 2.18 & 2.15 & 2.20 & 67.3 & 2.04 & SD & 0.34 & 0.4 & 0.51 & 5.1 & 0.13 \\
\hline PI 191203 & 2.23 & 2.12 & 2.25 & 74.5 & 2.20 & Min & 2.29 & 2.42 & 2.19 & 68.1 & 2.12 \\
\hline PI 341391 & 2.28 & 2.10 & 2.30 & 78.8 & 2.44 & Max & 3.15 & 3.47 & 3.53 & 80.0 & 2.40 \\
\hline PI 185723 & 2.29 & 2.12 & 2.21 & 69.0 & 2.00 & & & & & & \\
\hline PI 191145 & 2.34 & 2.41 & 2.37 & 66.5 & 2.20 & & & & & & \\
\hline PI 173503 & 2.40 & 2.43 & 2.41 & 63.8 & 1.84 & All accessions & & & & & \\
\hline \multirow[t]{2}{*}{ PI 134946} & 2.51 & 2.40 & 2.22 & 64.9 & 1.96 & Mean & 2.28 & 2.37 & 2.31 & 68.4 & 2.08 \\
\hline & & & & & & SD & 0.34 & 0.50 & 0.51 & 7.9 & 0.26 \\
\hline Mean & 2.22 & 2.13 & 2.19 & 70.1 & 2.12 & Min & 1.47 & 1.20 & 1.05 & 49.2 & 1.32 \\
\hline SD & 0.16 & 0.23 & 0.15 & 7.5 & 0.20 & Max & 3.15 & 3.47 & 3.53 & 81.7 & 2.44 \\
\hline Min & 1.95 & 1.70 & 1.90 & 60.0 & 1.80 & & & & & & \\
\hline Max & 2.51 & 2.43 & 2.41 & 79.3 & 2.44 & & & & & & \\
\hline
\end{tabular}

${ }^{\mathrm{a}}$ Mean of three field replications; ${ }^{\mathrm{b} F A E}=$ ferulic acid equivalents; ${ }^{\mathrm{C} G Y S}$-adj $=$ adjusted to grain yield per spike; ${ }^{\mathrm{d}} \mathrm{KW}$-adj $=$ adjusted to thousand-kernels weight; ${ }^{\text {SSC}}$ = DPPH scavenging capacity percentage; 'Trolox = 6-hydroxy-2,5,7,8-tetramethylchroman-2-carboxylic acid; $\mathrm{B}_{\mathrm{n} . \mathrm{d} .}=$ not determined due to insufficient grain. 
Roughly, we observed higher values of phenolic content than those reported by Lempereur et al. (1997) and Menga et al. (2010). Probably the different extracting procedures and/or the environmental conditions were effective in the variations of results, remarking the importance to evaluate with the same extracting procedure large sets of samples derived from plants grown in the same environment.

As far as AA is concerned, although a number of protocols has been reported for DPPH antioxidant assay (Sharma and Bhat 2009), some authors (Yu et al. 2002, Yu and Zhou 2004, Revanappa and Salimath 20011) adopted sample:DPPH r ratios similar to those we used. In spite of the fact they did not analyze tetraploid wheat, the results were comparable.

Table 3. Mean squares of soluble phenolic compounds (TSPC) and antioxidant activity (AA) of a tetraploid wheat collection grown at Valenzano (Bari, Italy) in 2010.

\begin{tabular}{lcccc}
\hline \multirow{2}{*}{$\begin{array}{l}\text { Source of } \\
\text { variation }\end{array}$} & df & TSPC & AA \\
\cline { 4 - 4 } Replications & & $3.425^{* * *}$ & $1032.890^{* * *}$ & $0.057^{* * *}$ \\
Samples & 2 & $0.302^{* * *}$ & $183.741^{* * *}$ & $0.012^{* * *}$ \\
Error & 112 & 0.035 & 25.954 & 0.002 \\
\hline
\end{tabular}

aean squares of AA as DPPH scavenging capacity percentage; ' ${ }^{\mathrm{D} M e a n}$ squares of AA as $\mu \mathrm{mol} / \mathrm{g}$ of 6-hydroxy-2,5,7,8-tetramethylchroman-2carboxylic acid; ***Significant differences at $p<0.001$.

In particular, Revanappa and Salimath (2011) assessed SC values up to about $80 \%$ in whole meal of 4 bread wheat cultivars, Yu and Zhou (2004) observed levels close to 75\% in bran and Yu et al. (2002) determined SC values up to $64 \%$ in wholegrain wheat-based breakfast cereals.

Among landraces and wild accessions, the highest TSPC levels were registered in ssp. dicoccoides: in particular PI 355459 and MG 4343 showed 3.15 and 3.04 mg FAE g$^{-1}$, respectively. The lowest levels were detected in ssp. polonicum and ssp. turanicum. Similarly, the highest mean value of AA was observed in the accessions of ssp. dicoccoides (74.1\% SC or $2.28 \mu \mathrm{mol}$ Trolox g ${ }^{-1}$ ), according to the highest TSPC measured in the same group. These observations could be justified by the effect of domestication in ssp. polonicum and ssp. turanicum, absent in ssp. dicoccoides. The latter could be richer in phenolics due to the role played by these substances in disease resistance and plant protection against oxidative stress (Daniel et al. 1999), that are essential for wild accessions. These data point out the potential of wild plant materials as genetic resource in breeding programs aimed to increase phenolic content.

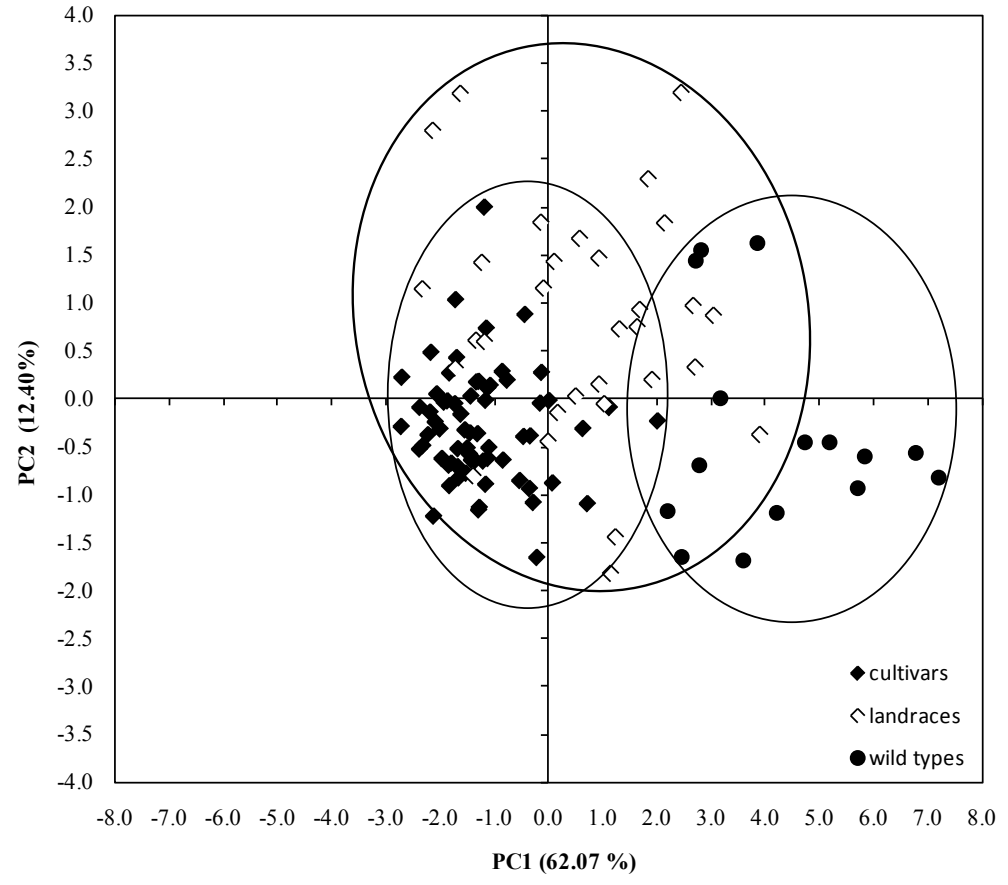

Fig. 1. Scatter plot of the observation scores of the first two principal components PC1 and PC2 obtained using the analytical data and accounting for about $75 \%$ of total variance of a tetraploid wheat collection grown at Valenzano (Bari, Italy) in 2010. The accessions were grouped in cultivars (ssp. durum), landraces (ssp. turanicum, ssp. polonicum, ssp. turgidum, ssp. carthlicum) and wild types (ssp. dicoccum and ssp. dicoccoides). 
The principal component analysis of TSPC and AA data was performed, including also data related to grain yield measured in the same collection (KW and GYS, data not shown) and some qualitative characteristics, namely GPC, PPO activity, and BI of whole meal and dough, analyzed in a previous work (data sets reported in Taranto et al. 2012). Figure 1 plots the observation scores of the first two components, accounting for about $75 \%$ of total variance for data. In particular, PC1 explained $62 \%$ of variability and enabled to distinguish the wild types from the majority of durum cultivars, while the landraces showed characteristics in-between. The ellipses, corresponding to the $95 \%$ confidence limit, can be assumed to define group boundaries. Overlapping among durum cultivars and landraces, in particular ssp. turanicum and ssp. polonicum, was observed. A few cultivars fell into the PC1 positive quadrant (namely 'Timilia', 'Belfuggito', 'Kiperounda', 'Polesine' and 'Aziziah'), probably because they are selections of local or exotic landraces (as in case of 'Timilia', 'Kiperounda', 'Aziziah', and 'Polesine', being the latter Forlani $\times$ Aziziah) or have ssp. dicoccoides in the pedigree (as for Belfuggito).

Figure 2 plots the variable loadings of the first two components: PC1 was positively correlated with TSPC, AA, GPC, PPO, and BI, while was negatively correlated with yield components. Hence, the cultivars were linked to GYS and KW; on the contrary, the wild types were related to grain physico-chemical characteristics. Apart the efforts made to improve GYS and KW, probably an indirect selection for low TSPC occurred in many of the examined cultivars due to its positive correlation with brownness (Table 4), usually considered an undesired character.

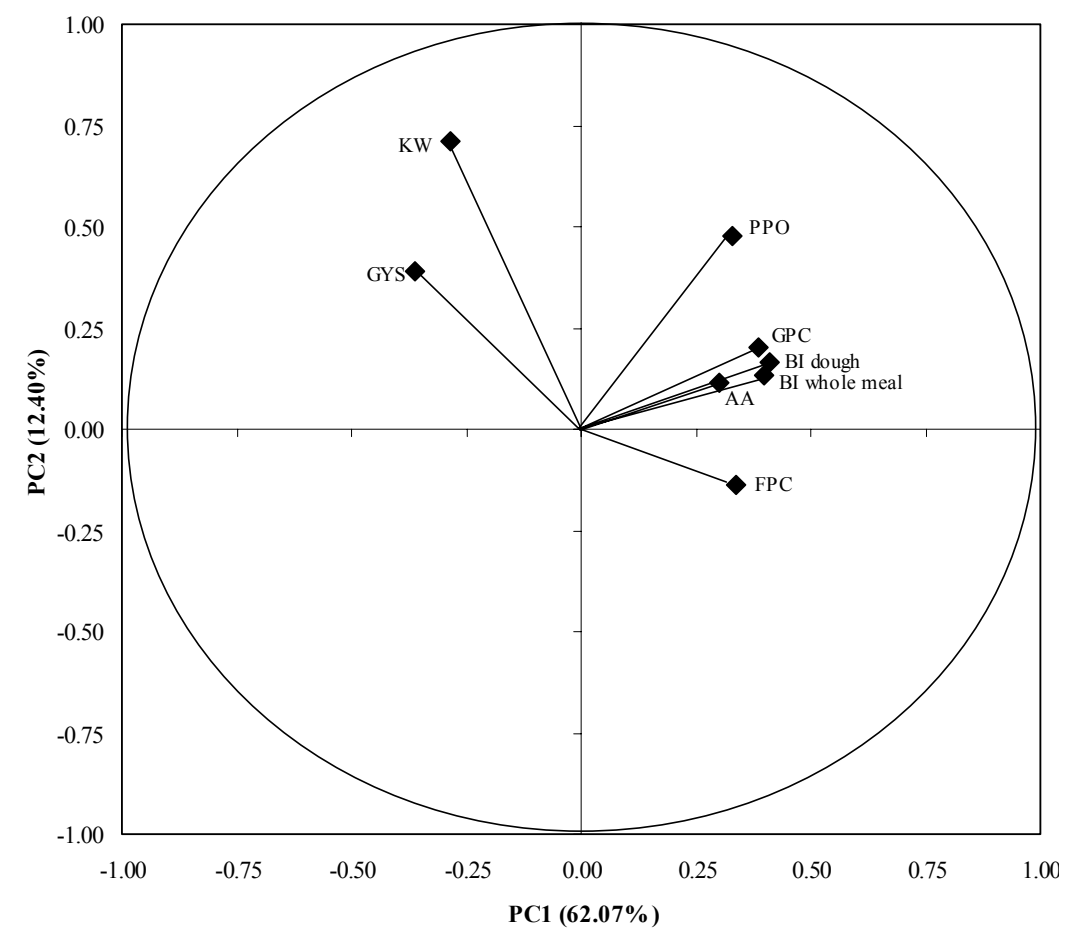

Fig. 2. Variables loading plot for the first two principal components PC1 and PC2 obtained using the analytical data evaluated in a tetraploid wheat collection grown at Valenzano (Bari, Italy) in 2010. TSPC = soluble phenolic compounds; $A A=$ antioxidant activity; $G P C=$ grain protein content; $\mathrm{BI}=$ brown index; $\mathrm{KW}=$ thousand-kernels weight; $\mathrm{GYS}=$ grain yield per spike.

\section{Correlation of TSPC with yield components and quality characteristics}

Table 4 reports the correlation between TSPC and AA, as well as with data of KW and GYS (data not shown) and data of GPC, PPO activity, and BI of whole meal and dough (data reported in Taranto et al 2012). The TSPC content was positively correlated $(p<0.001)$ with $\mathrm{AA}, \mathrm{GPC}, \mathrm{PPO}$, and $\mathrm{BI}$ of whole meal and dough, while significant negative correlations $(p<0.001)$ were observed with grain yield indices (GYS and KW). Since TSPC are mainly located in the outer layers of the caryopsis (Lempereur et al. 1997, Acquistucci et al. 2013), the observed negative TSPC-yield correlations might be attributed to dilution of phenolics in larger grains. Grain size, in turn, is known to be ruled by environmental factors and genetic components (Mpofu et al. 2006). Hence, for better investigating the correlations between TSPC and the other traits, a statistical procedure for estimating adjusted values was 
A. Pasqualone et al. (2014) 23: 307-316

applied. The values of TSPC adjusted to KW and GYS (reported in Tables 1 and 2) allow the analysis of TSPC independently of variations in KW and GYS. By comparing the correlations with observed and adjusted TSPC values, it appears that the $r$ coefficients of all correlations increased when adjusted values were considered, except for GPC and PPO in case of the KW-adj TSPC values.

The positive correlation with AA remarks the antioxidant effect of phenolics, although the $r$ value was relatively low. TSPC were only a part of total phenolics; a stronger correlation was reported by Adom et al. (2003) with total phenolics (the sum of free, soluble conjugate, and insoluble bound phenolics). On the other hand, Heimler et al. (2010) found no correlation between TSPC and AA in 9 durum cultivars: the small number of samples probably might account for the lack of significant correlation.

As regards to the positive correlation between TSPC and both PPO activity and BI of whole meal and dough, similar correlations have been reported in hexaploid wheat (McCallum and Walker 1990). However, durum wheat shows significantly lower PPO activity (Bernier and Howes 1994, Feillet et al. 2000): a rapid test for detecting contamination of durum by hexaploid wheat is based on this difference (Mahoney and Ramsay 1992). The correlation between TSPC and both PPO and BI confirmed the key role of phenolics in browning: PPO catalyses the oxidation of phenols to quinones in the presence of molecular oxygen. Moreover, PPO-generated quinones are subsequently converted to melanins by self-polymerization or condensation with amino acids or proteins (Matheis and Whitaker 1984). Besides, PPO activity has been associated to undesired browning of dough and noodles by many authors (Mahoney and Ramsay 1992, Feillet et al. 2000, Fuerst et al. 2006, Delvecchio and Pasqualone 2012, Taranto et al. 2012).

The correlations between TSPC, PPO activity and BI of whole meal indicate that phenolics start to be oxidized in the kernel, so as to originate the inherent brownness of endosperm (Feillet et al. 2000). Higher $r$ values were observed considering the dough (Table 4), remarking that the addition of water, essential to obtain end-products, enables the whole manifestation of the enzyme activity. Assessing dough color in standard conditions is a fast and simple method to check the contemporary presence of phenolics and PPO, and to predict pasta color (Pasqualone et al. 2005).

Among the cultivars with high TSPC content, special interest was put towards 'Timilia', the cultivar used to prepare an Italian bread awarded by Slow Food Presidium mark called "Pane nero di Castelvetrano". This bread, produced in Sicily area, is typically characterised by brownish crumb (Pasqualone 2012). The notably high TSPC level of 'Timilia', coupled to high PPO activity (Taranto et al. 2012), explains the intense brownness of the end-product.

Table 4. Correlation coefficients ( $r$ ) among observed and adjusted values of soluble phenolic compounds and some yield and quality characteristics in a collection of tetraploid wheat grown at Valenzano (Bari, Italy) in 2010.

\begin{tabular}{lccccccc}
\hline & $\mathrm{AA}^{\mathrm{a}}$ & $\mathrm{GYS}^{\mathrm{b}}$ & $\mathrm{KW}$ & $\mathrm{GPC}$ & $\begin{array}{c}\mathrm{Bl}^{\mathrm{e}} \\
\text { Whole Meal }\end{array}$ & $\begin{array}{c}\mathrm{Bl}^{\mathrm{e}} \\
\text { Dough }\end{array}$ & $\mathrm{PPO}^{f}$ \\
\hline TSPC $^{\mathrm{g}}$ & $0.396^{* * *}$ & $-0.561^{* * *}$ & $-0.491^{* * *}$ & $0.606^{* * *}$ & $0.568^{* * *}$ & $0.628^{* * *}$ & $0.467^{* * *}$ \\
GYS-adj TSPC $^{\text {h }}$ & $0.463^{* * *}$ & $-0.804^{* * *}$ & $-0.642^{* * *}$ & $0.711^{* * *}$ & $0.647^{* * *}$ & $0.701^{* * *}$ & $0.519^{* * *}$ \\
KW-adj TSPC & $0.447^{* * *}$ & $-0.697^{* * *}$ & $-0.748^{* * *}$ & $0.590^{* * *}$ & $0.622^{* * *}$ & $0.656^{* * *}$ & $0.430^{* * *}$
\end{tabular}

${ }^{\mathrm{a} A A}=$ antioxidant activity; ${ }^{\mathrm{b}} \mathrm{GYS}=$ grain yield per spike; ${ }^{\mathrm{c}} \mathrm{KW}=$ thousand-kernels weight; ${ }^{\mathrm{d}} \mathrm{GPC}=$ grain protein content; ${ }^{\mathrm{e}} \mathrm{BI}=$ brown index; ${ }^{\mathrm{f}} \mathrm{PPO}=$ polyphenol oxidase activity; ${ }^{\mathrm{g} T S P C}=$ Soluble phenolic compounds; ${ }^{\mathrm{h}} \mathrm{GYS}$-adj TSPC = TSPC values adjusted to GYS; ${ }^{\mathrm{K}} \mathrm{KW}$-adj TSPC = TSPC values adjusted to $\mathrm{KW} ;{ }^{* * *}$ Significant differences at $p<0.001$.

Particularly interesting, also, was cv. 'Langdon', that showed a relatively high TSPC level (2.25 mg FAE g-1). In spite of that, this cultivar is known to have low PPO activity and, consequently, low BI (Fuerst et al. 2006, Taranto et al. 2012) remarking that: $i$ ) to provoke browning is needed the simultaneous presence of both substrates and enzyme; ii) in spite of the above reported correlations, it is possible to select wheats with high TSPC and AA but characterized by low incidence of undesired traits, that can be used to realize end-products with improved healthy features.

About the positive correlation between TSPC and GPC, phenylalanine-derived phenolics have a $\mathrm{C}$ skeleton but, from a biosynthetic perspective, they are more similar to N-based compounds, such as proteins. A relationship 
A. Pasqualone et al. (2014) 23: 307-316

between proteins and phenolic compounds, sharing the same precursor phenylalanine, has been reported (Jones and Hartley 1999), and increased levels of the precursor may lead to higher amounts of both the final products. Moreover, GPC has been found to be positively correlated to BI of whole meal and dough (Taranto et al. 2012) due to the above reported browning mechanism (Matheis and Whitaker 1984) and, since browning intensity is correlated with TSPC level, it is reasonable to expect that TSPC and GPC are related. A water-soluble copper-containing basic protein, assumed to be responsible for pasta brownness, seems to consist of a complex between phenolics and PPO developed during kernel maturation (Feillet et al. 2000).

\section{Conclusions}

The obtained data show that tetraploid wheat may constitute a valuable source of phenolic substances. The wheat species and cultivars examined exhibited significant differences in TSPC and in DPPH radical scavenging capacities. This study could provide useful information regarding the best wheats to be used to obtain end-products with improved healthy features coupled to low incidence of undesired characteristics.

\section{Acknowledgement}

The authors acknowledge the financial support of MIUR in the framework of the Project PON/01_01145/8 "ISCOCEM".

\section{References}

Abdel-Aal, E.S.M. \& Rabalski, I. 2008. Bioactive compounds and their antioxidant capacity in selected primitive and modern wheat species. Open Agriculture Journal 2: 7-14.

Acquistucci, R., Melini, V., Carbonaro, M. \& Finotti, E. 2013. Bioactive molecules and antioxidant activity in durum wheat grains and related millstream fractions. International Journal of Food Science and Nutrition 64: 959-967.

Adom, K.K., Sorrells, M.E. \& Liu, R.H. 2003. Phytochemical profiles and antioxidant activity of wheat varieties. Journal of Agricultural and Food Chemistry 51: 7825-7834.

Bernier, A.M. \& Howes, N.K. 1994. Quantification of variation in tyrosinase activity among durum and common wheat cultivars. Journal of Cereal Science 19: 157-159.

Beta, T., Nam, S., Dexter, J.E. \& Sapirstein, H.D. 2005. Phenolic content and antioxidant activity of pearled wheat and roller-milled fractions. Cereal Chemistry 82: 390-393.

Daniel, O., Meier, M.S., Schlatter, J. \& Frischknecht, P. 1999. Selected phenolic compounds in cultivated plants: ecologic functions, health implications, and modulation by pesticides. Environmental Health Perspectives 107: 109-114.

Delvecchio, L.N. \& Pasqualone, A. 2012. Production trials of fresh pasta enriched with phenolic compounds extracted from wheat by $\mathrm{KOH}$-induced hydrolysis. Progress in Nutrition 4: 247-251.

De Munter, J. S. L., Hu, F. B., Spiegelman, D., Franz, M. \& Van Dam, R. M. 2007. Whole grain, bran, and germ intake and risk of type 2 diabetes: a prospective cohort study and systematic review. PLoS Medicine 4: 1385-1395.

Dinelli, G., Segura Carretero, A., Di Silvestro, R., Marotti, I., Fu, S., Benedettelli, S., Ghiselli, L. \& Gutierrez, A.F. 2009. Determination of phenolic compounds in modern and old varieties of durum wheat using liquid chromatography coupled with time-of-flight mass spectrometry. Journal of Chromatography A 1216: 7229-7240.

Feillet, P., Autran, J.C. \& Icard-Vernière, C. 2000. Pasta brownness: an assessment. Journal of Cereal Science 32: 215-233.

Feldman, M. 1995. Wheats. In: Smartt, J., Simmonds, N.W. (eds.). Evolution of crop plants. Harlow, UK: Longman Scientific and Technical. p. 185-192.

Ferguson, L.R. \& Harris, P.J. 1999. Protection against cancer by wheat bran: role of dietary fibre and phytochemicals. European Journal of Cancer Prevention 8: 17-25.

Fuerst, E.P., Anderson, J.V. \& Morris, C.F. 2006. Delineating the role of polyphenol oxidase in the darkening of alkaline wheat noodles. Journal of Agricultural and Food Chemistry 54: 2378-2384.

Heimler, D., Vignolini, P., Isolani, L., Arfaioli, P., Ghiselli, L. \& Romani, A. 2010. Polyphenol content of modern and old varieties of Triticum aestivum L. and T. durum Desf. grains in two years of production. Journal of Agricultural and Food Chemistry 58: 7329-7334.

Jones, C.G. \& Hartley, S.E. 1999. A protein competition model of phenolic allocation. Oikos 86: 27-44.

Klepacka, J. \& Fornal, L. 2006. Ferulic acid and its position among the phenolic compounds of wheat. Critical Reviews in Food Science and Nutrition 46: 639-647.

Laidò, G., Mangini, G., Taranto, F., Gadaleta, A., Blanco, A., Cattivelli, L., Marone, D., Mastrangelo, A.M., Papa, R. \& De Vita, P. 2013. Genetic diversity and population structure of tetraploid wheats (Triticum turgidum L.) estimated by SSR, DArT and pedigree data. PLoS ONE 8: e67280.

Lempereur, I., Rouau, X. \& Abecassis, J. 1997. Genetic and agronomic variation in arabinoxylan and ferulic acid contents of durum wheat (Triticum durum L.) grain and its milling fractions. Journal of Cereal Science 25: 103-110. 
Mahoney, R.R. \& Ramsay, M. 1992. A rapid tyrosinase test for detecting contamination of durum wheat. Journal of Cereal Science 15: 267-270.

Matheis, G. \& Whitaker, J.R. 1984. Modification of proteins by polyphenol oxidase and peroxidase and their products. Journal of Food Biochemistry 8: 137-162.

Mateo Anson, N., van den Berg, R., Havenaar, R., Bast, A. \& Haenen, G.R. 2009. Bioavailability of ferulic acid is determined by its bioaccessibility. Journal of Cereal Science 49: 296-300.

McCallum, J.A. \& Walker, J.R.L. 1990. O-diphenol oxidase activity, phenolic content and colour of new Zealand wheats, flours and milling streams. Journal of Cereal Science 12: 83-96.

Menga, V., Fares, C., Troccoli, A., Cattivelli, L. \& Baiano, A. 2010. Effects of genotype, location and baking on the phenolic content and some antioxidant properties of cereal species. International Journal of Food Science and Technology 45: 7-16.

Moore, J. \& Hao, J. 2012. Antioxidant and health promoting properties of wheat (Triticum spp.). In: Yu, L., Tsao, R. \& Shahidi F. (eds.). Cereals and pulses: nutraceutical properties and health benefits. Chichester, UK: John Wiley \& Sons. p. 113-126.

Mpofu, A., Sapirstein, H.D. \& Beta, T. 2006. Genotype and environmental variation in phenolic content, phenolic acid composition, and antioxidant activity of hard spring wheat. Journal of Agricultural and Food Chemistry 54: 1265-1270.

Pasqualone, A. 2012. Italian durum wheat breads. In: Pedrosa Silva Clerici M.T. (ed.). Bread consumption and health. Hauppauge, New York, USA: Nova Publisher Inc. p. 57-80.

Pasqualone, A., Clodoveo, M.L., Blanco, A. \& Simeone, R. 2005. Valutazione dell'imbrunimento enzimatico in sfarinati di frumento duro: confronto di metodi spettrofotometrici e colorimetrici. Tecnica Molitoria 56: 116-122. (in Italian).

Pasqualone, A., Delvecchio, L.N., Lacolla, G., Piarulli, L., Simeone, R. \& Cucci, G. 2014. Effect of composted sewage sludge on durum wheat: productivity, phenolic compounds, antioxidant activity, and technological quality. Journal of Food, Agriculture and Environment 12: 276-280.

Revanappa, S.B. \& Salimath, P.V. 2011. Phenolic acid profiles and antioxidant activities of different wheat (Triticum aestivum L.) varieties. Journal of Food Biochemistry 35: 759-775.

Sharma, O.P. \& Bhat, T.K. 2009. DPPH antioxidant assay revisited. Food Chemistry 113: 1202-1205.

Soobrattee, M.A., Neergheen, V.S., Luximon-Ramma, A., Aruoma, O.I. \& Bahorun, T. 2005. Phenolics as potential antioxidant therapeutic agents: mechanism and actions. Mutation Research/Fundamental and Molecular Mechanisms of Mutagenesis 579: $200-213$.

Taranto, F., Delvecchio, L.N., Mangini, G., Del Faro, L., Blanco, A. \& Pasqualone, A. 2012. Molecular and physic-chemical evaluation of enzymatic browning of whole meal and dough in a collection of tetraploid wheats. Journal of Cereal Science 55: 405-414.

Tucker, G. \& Robards, K. 2008. Bioactivity and structure of biophenols as mediators of chronic diseases. Critical Reviews in Food Science and Nutrition 48: 929-966.

Van Hung, P., Hatcher, D.W. \& Barker, W. 2011. Phenolic acid composition of sprouted wheats by ultra-performance liquid chromatography (UPLC) and their antioxidant activities. Food Chemistry 126: 1896-1901.

Verma, B., Hucl, P. \& Chibbar, R.N. 2008. Phenolic content and antioxidant properties of bran in 51 wheat cultivars. Cereal Chemistry 85: 544-549.

Yu, L. 2008. Wheat antioxidants. Chichester, UK: John Wiley \& Sons. 288 p.

Yu, L., Perret, J., Davy, B., Wilson, J. \& Melby, C.L. 2002. Antioxidant properties of cereal products. Journal of Food Science 67: 2600-2603.

Yu, L. \& Zhou, K. 2004. Antioxidant properties of bran extracts from 'Platte' wheat grown at different locations. Food Chemistry 90: 311-316.

Zhou, K. \& Yu, L. 2004. Effects of extraction solvent on wheat bran antioxidant activity estimation. LWT - Food Science and Technology 37: 717-721.

Żuchowski, J., Kapusta, I., Szajwaj, B., Jończyk, K. \& Oleszek, W. 2009. Phenolic acid content of organic and conventionally grown winter wheat. Cereal Research Communications, 37: 189-197. 